\title{
Synthetic approaches towards huperzine A and B
}

\author{
Shariar Md. Abu Sohel and Till Opatz* \\ Department of Organic Chemistry, Johannes Gutenberg-University, Duesbergweg 10-14, 55128 \\ Mainz, Germany \\ E-mail:opatz@uni-mainz.de
}

DOI: $\underline{\text { http://dx.doi.org/10.3998/ark.5550190.p008.313 }}$

\begin{abstract}
Huperzine A and B are potent acetylcholinesterase inhibitors and promising against Alzheimer's disease. Completed and formal total syntheses of these medically relevant alkaloids are presented and discussed.
\end{abstract}

Keywords: Huperzine A, huperzine B, total synthesis, alkaloids, Alzheimer's disease

\section{Table of Contents}

1. Introduction

2. Huperzine A

3. Huperzine B

4. References

\section{Introduction}

The lycopodium alkaloids are a structurally diverse and extensively studied alkaloid family containing quinolizine, pyridine or $\alpha$-pyridone moieties. ${ }^{1-2}$ These naturally occurring nitrogen containing molecules are known to possess a wide range of biological activities. Some lycopodium alkaloids exert potent inhibition of acetylcholinesterase ${ }^{3-4}$ and exhibit neuroprotective properties. ${ }^{5-9}$ It has been documented that huperzine A increases the efficiency of learning as well as memory in animals, and it shows promise in the treatment of Alzheimer's disease (AD). ${ }^{10-11}$ Because of its unparalleled biological profile to combat AD, it has recently gained considerable attention as a therapeutic agent against dementia ${ }^{12-15}$ and is being used as clinical drug in China. ${ }^{16}$ A number of clinical reports reveal huperzine $A$ to be capable of facilitating cholinergic neurotransmission by increasing the levels of acetylcholine in the central nervous system. ${ }^{17}$ Interestingly, its pharmacological profile is found to be superior to that of tetrahydroaminoacridine (Tacrine), an FDA-approved drug for the treatment of $\mathrm{AD}{ }^{18}$ Its 
superiority over other drugs can be partly attributed to its lower toxicity. ${ }^{18}$ Huperzine B possesses an even higher therapeutic index than huperzine $A$ which is in agreement with its longer duration of action. ${ }^{19}$ Both huperzine $\mathrm{A}$ and huperzine $\mathrm{B}$ were isolated from the Chinese club moss Huperzia serrata ${ }^{20}$ which has a long history of use as Chinese folk medicine against various ailments like contusions, strains, swellings, and schizophrenia. Later on, huperzine A was also isolated from the New Zealand club moss Lycopodium varium. ${ }^{21}$

Although numerous strategies for the total syntheses of huperzines and analogues thereof have been reported, a systematic review of this topic is lacking. The present review addresses this gap and aims to give the readers an up to date overview of the synthetic routes to the huperzines with a special emphasis on the strategies for the construction of the bicyclo[3.3.1] ring system. We will focus on completed and formal total syntheses of huperzine A and B while partial syntheses and incomplete or unsuccessful synthetic approaches will remain out of scope because of space constraints.
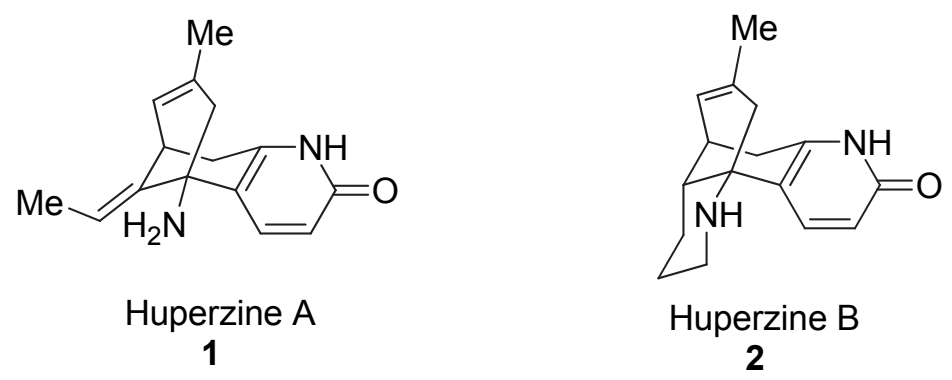

Figure 1. Structure of the huperzines.

\section{Huperzine A}

Huperzine A (1) presents a fascinating bicyclo[3.3.1]nonane unit fused to a 2-pyridone moiety. The bicyclo[3.3.1]skeleton is embellished with an ethylidene group and a free primary amine at the bridgehead carbon (Fig 1). The impressive biological profile in conjunction with its limited access from natural sources has stimulated many synthetic efforts towards huperzine A and resulted in a number of successful total syntheses of this alkaloid. The first of its kind produced the racemic material and were independently accomplished by Kozikowsky ${ }^{22-23}$ and Qian $\& \mathrm{Ji}^{24}$ In both approaches, the same $\beta$-keto ester $\mathbf{3}$ was reacted with methacrolein in a domino Michaelaldol addition to set up the bicyclo[3.3.1] framework (Scheme 1). The alcohol 4 thus obtained was converted into olefin 5 through mesylation and subsequent $\beta$-elimination. However the elimination step gave only a moderate yield $(\sim 50 \%)$ because the precursor alcohol 4 was a mixture of diastereomers of which only the isomer with an axial $\mathrm{OH}$ group and an equatorial methyl substituent reacted. The exocyclic double bond was installed by a Wittig olefination which produced an $E / Z$-mixture in favor of the the undesired $(Z)$ isomer. At this point Kozikowsky's route differed from Qian and Ji's approach. In the former, the double bond was 
isomerized in a radical reaction using thiophenol and azobisisobutyronitrile (AIBN) producing predominantly the $(E)$ isomer. Subsequent saponification resulted in selective hydrolysis of the $(E)$ isomer. The $(Z)$ isomer was reluctant to undergo hydrolysis as its ester functionality was sterically more congested. In contrast, Qian and Ji saponified the Wittig product 6 itself while the $(E)$-isomer underwent saponification preferentially and the resulted acid $\mathbf{8}$ was separated easily from the unreacted $(Z)$ form of the ester. Huperzine A was obtained from acid 8 through subsequent Curtius rearrangement, O-demethylation and hydrolysis. An asymmetric version of this synthesis was also accomplished by Kozikowski et al. by using 8-phenylneomenthol as a chiral auxiliary which afforded the natural enantiomer (-) huperzine A. ${ }^{25}$ Another asymmetric version $^{26}$ of the aforementioned domino Michael-aldol sequence was implemented by employing a chiral cinchona base (11) which converted $\beta$-keto ester 3 into alcohol 4 in $64 \%$ ee. This asymmetric tandem Michael-aldol reaction has also been realized recently by Yao and coworkers $^{27}$ under the influence of the quinine-derived chiral thiourea organocatalyst $\mathbf{1 2}$ to give rise to the alcohol 4 in $92 \%$ enantiomeric excess.
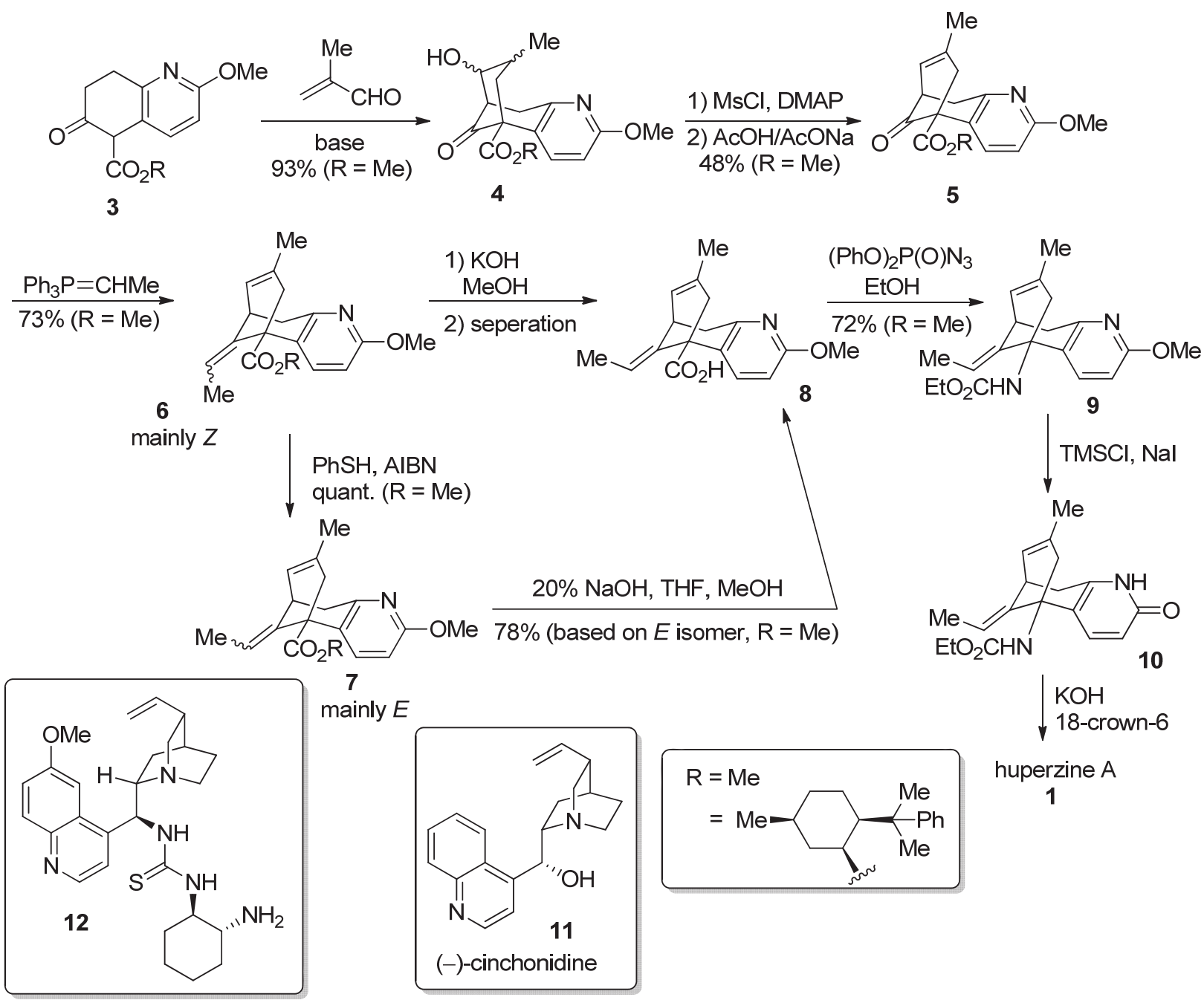

Scheme 1. Synthesis of huperzine A via domino Michael-aldol addition. 
Kozikowski disclosed a second generation synthesis of huperzine A in which he exploited a palladium catalyzed annulation of $\beta$-keto ester 13 with 2-methylenepropane-1,3-diol diacetate (Scheme 2) ${ }^{28,18}$ The exocyclic double bond in the product $\mathbf{1 4}$ was isomerized with triflic acid to obtain olefin 15. Huperzine A was obtained from 15 by the same sequence as in his racemic route. An alternative route to hupezine A from the exocyclic olefin 14 has also been reported. In this synthesis, 14 was subjected to a Wittig olefination to give an $E / Z$ mixture of olefin 16 rich in the undesired $(Z)$ isomer. A subsequent radical isomerization led to a 95:5-mixture of olefins favoring the desired $(E)$-form. Upon saponification, the $(E)$ isomer preferentially underwent hydrolysis to the corresponding acid $\mathbf{1 8}$ while the $(Z)$-form remained untouched. The acid was smoothly converted into carbamate 19 by Curtius rearrangement. TMSI mediated deprotection and triflic acid induced isomerization of the exocyclic double bond finally<smiles>COC(=O)C1C(=O)CCc2nc(OC)ccc21</smiles>

13

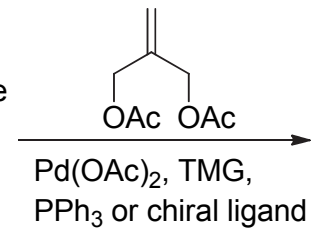

$\mathrm{Ph}_{3} \mathrm{P}=\mathrm{CHMe}$

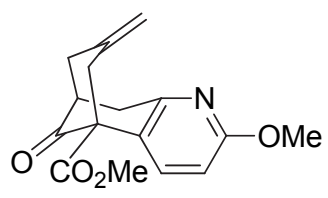

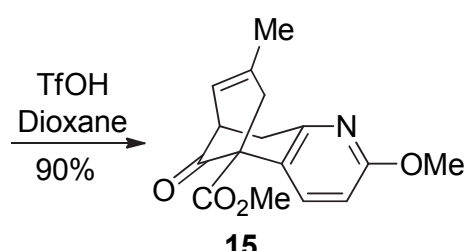

15

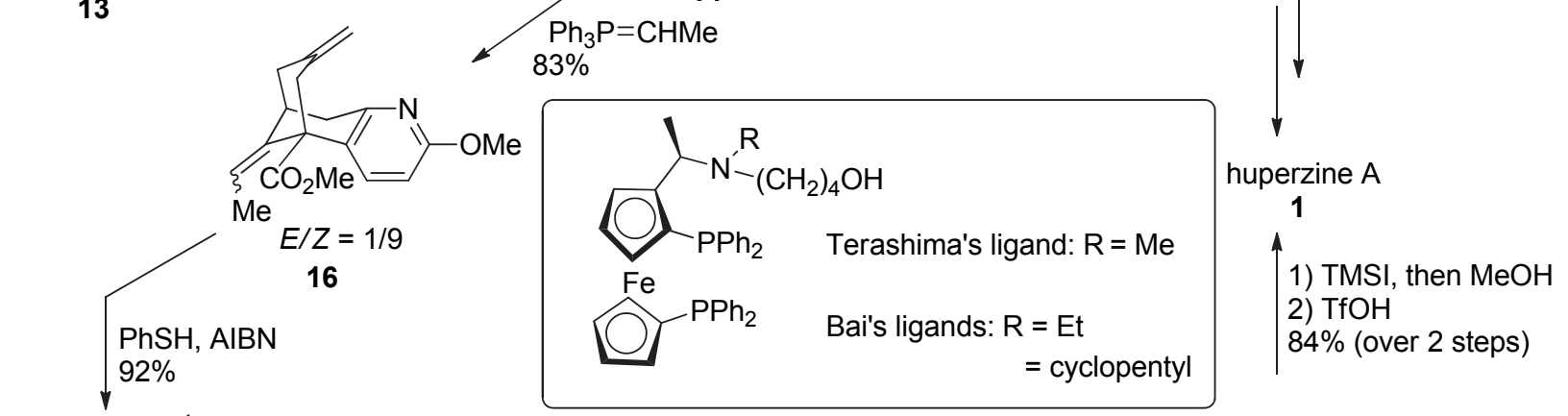

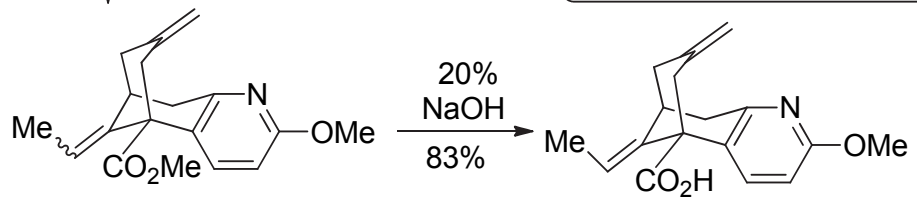

$E / Z=19 / 1$

17

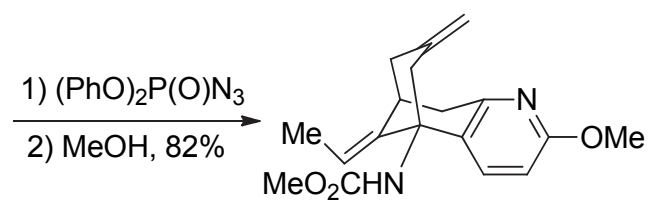

19

Scheme 2. Synthesis of huperzine A via Pd-catalyzed annulations.

furnished the natural product. These routes not only improved the overall yield of the sequence but also bypassed the low-yielding elimination step described in the previous approach. The Pdcatalyzed bicycloannulation strategy was adopted independently by Terashima and Bai to develop asymmetric routes which provided the olefin 14 in $>90 \%$ ee. ${ }^{29-30}$ Both groups employed ferrocene based chiral phosphine ligands for inducing asymmetry in this common key step. A chiral auxiliary based version of Kozikowski's Pd-catalyzed bicycloannulation to huperzine was demonstrated by Langlois et al. (Scheme 3). ${ }^{31-32}$ Here, the auxiliary was attached by reacting the 
$\beta$-keto ester 13 with $(1 R, 2 S)$-2-phenylcyclohexanol. After successive Pd-catalyzed bicycloannulation, Wittig olefination, $E / Z$ isomerization and exo/endo isomerization of the olefinic double bond, the chiral handle was detached by LAH reduction. This route can be regarded as a formal synthesis of unnatural $(+)$-huperzine as the resulting primary alcohol $\mathbf{2 3}$ was an intermediate in Kozikowsky's asymmetric synthesis. ${ }^{25}$

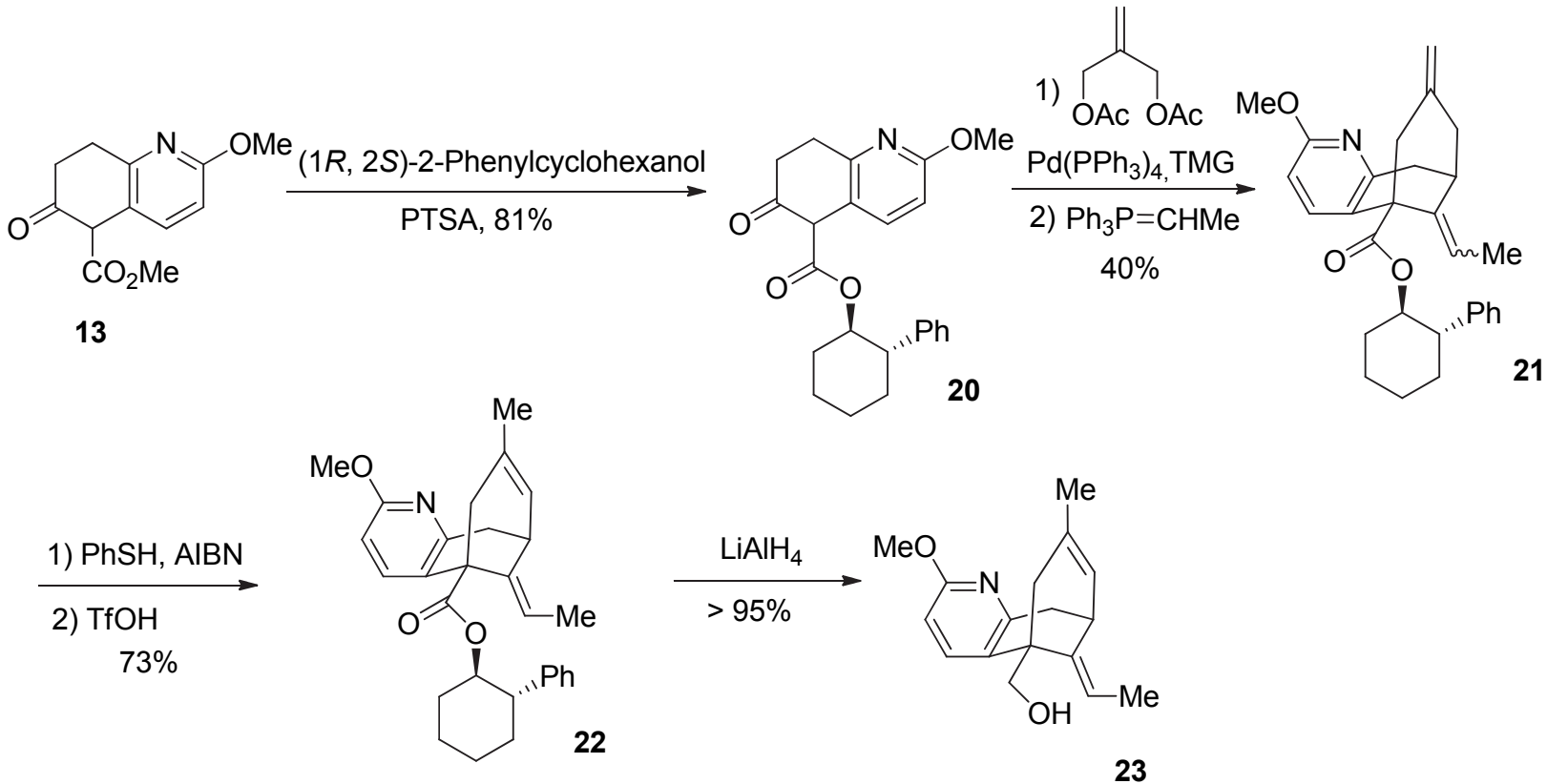

Scheme 3. Langlois formal synthesis of (+)-huperzine A via Pd-catalyzed annulations.

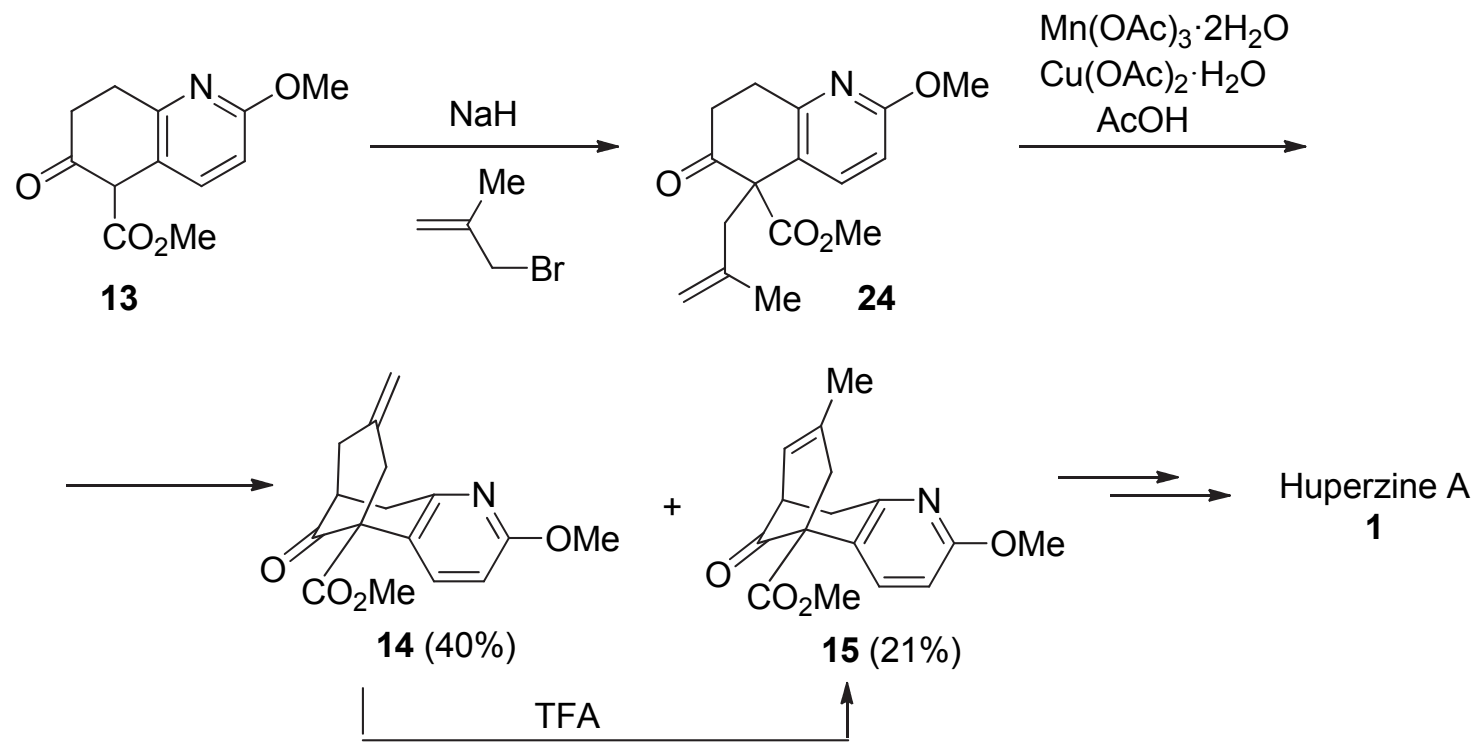

Scheme 4. Lee's radical cyclization for the synthesis of huperzine A. 
Lee $^{33}$ formulated a synthesis of huperzine A which relies on a Mn(III) mediated oxidative radical cyclization on the suitably substituted $\beta$-keto ester $\mathbf{2 4}$ to give the desired bicyclic product as a regioisomeric mixture (Scheme 4). Again, the undesired exo isomer 14 was easily converted into the endo isomer 15 by treatment with TFA. The precursor for the radical cyclization was readily derived from $\beta$-keto ester $\mathbf{1 3}$ by a simple methallylation reaction.
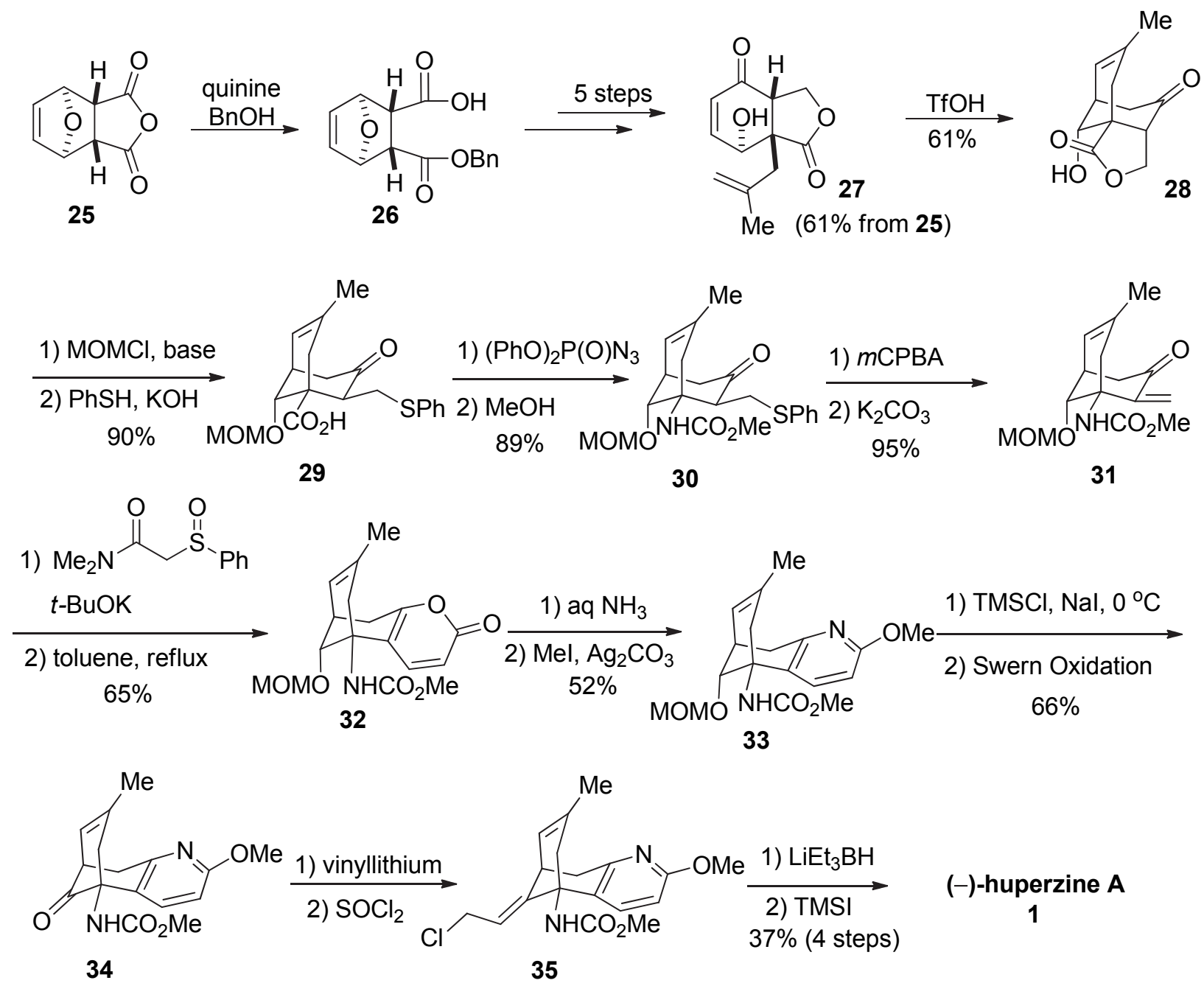

Scheme 5. Fukuyama's synthesis of (-)-huperzine A.

An ingenious approach to optically pure (-)-huperzine was reported by Fukuyama et al. who introduced the ethylidene and pyridone moieties in the molecule in a very unique manner. ${ }^{34}$ As illustrated in Scheme 5, their synthesis commenced with the meso-anhydride 25 which, upon desymmetrization, gave the acid 26 with $99 \%$ ee. Allylated lactone 27 was obtained from compound $\mathbf{2 6}$ in only five steps. Treatment of $\mathbf{2 7}$ with triflic acid led to cation-olefin cyclization establishing the required bicyclo[3.3.1] skeleton. The next tasks were to install the ethylidene and pyridone moieties. Protection of hydroxyl group of $\mathbf{2 8}$ followed by thiolysis of the lactone 
gave carboxylic acid 29 which was rearranged with diphenylphosphoryl azide (DPPA) to give carbamate 30. Oxidation of the thioether to the sulfoxide and subsequent elimination furnished enone 31. Michael addition of a sulfinylamide anion to enone $\mathbf{3 1}$ occurred smoothly to afford a $\delta$-ketoamide which was subjected to a cyclization/desulfination sequence in refluxing toluene. The pyrone 32 thus obtained was treated with ammonia to give rise to 2-pyridone which was further protected as the 2-methoxypyridine (33). Selective deprotection of the MOM group, Swern oxidation and treatment of the resulting ketone $\mathbf{3 4}$ with vinyllithium led to formation of an allylic carbinol which was subjected to an $\mathrm{S}_{\mathrm{N}} 2$ ' reaction with chloride to give allyl chloride 35 . In this compound, the $E$-geometry is preferred over $Z$-geometry to avoid the steric encumberment with the preinstalled carbamate functionality at the bridgehead. Hydride reduction of the allylic chloride 35 and TMSI mediated deprotection afforded (-)-huperzine in 1.8\% overall yield.

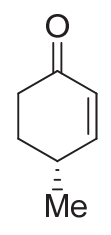

36

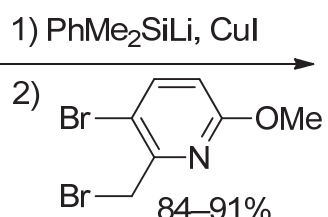

$84-91 \%$

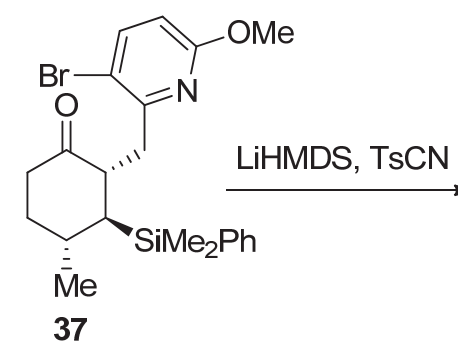

37

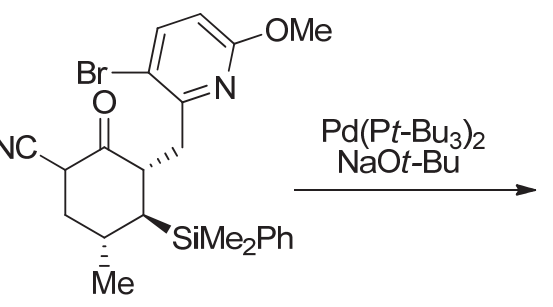

38

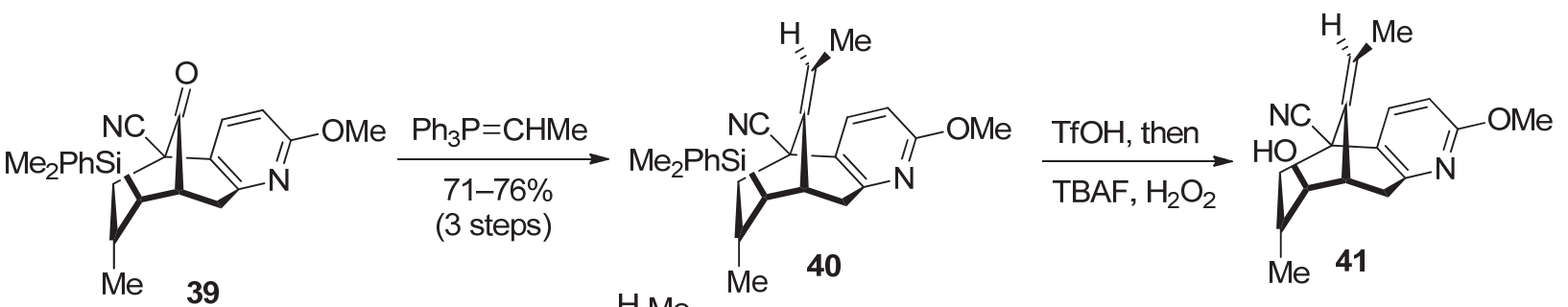

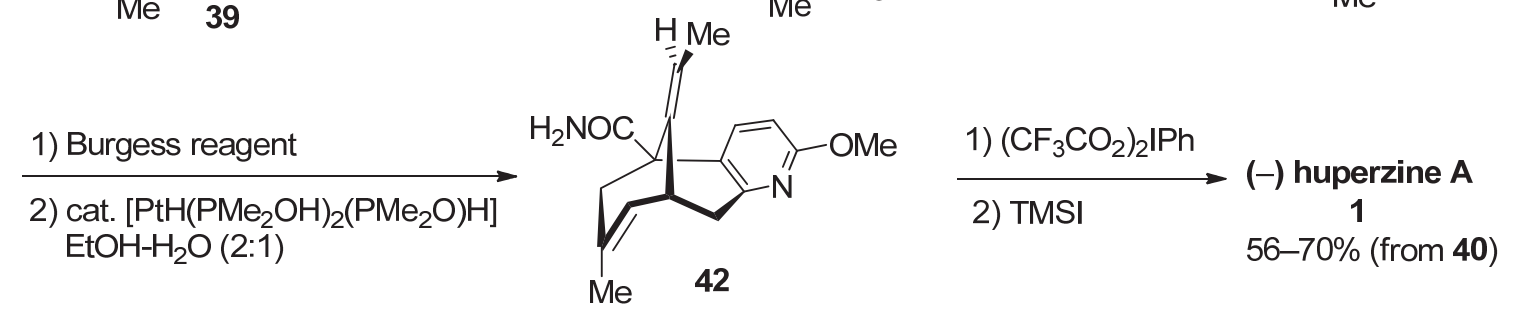

Scheme 6. Herzon's route to (-)-huperzine A.

Herzon et al ${ }^{35}$ have developed a scalable synthesis of (-)-huperzine (Scheme 6). In this chiral pool approach, the (+)-pulegone derived enone $\mathbf{3 6}$ was chosen as the starting material. It underwent Michael addition of lithium dimethylphenylsilylcuprate to give an enolate which was quenched with 3-bromo-2-(bromomethyl)-6-methoxypyridine to afford ketone $\mathbf{3 7}$ as a single diastereomer. Electrophilic cyanation was effected after kinetically controlled deprotonation and the obtained $\alpha$-cyanoketone $\mathbf{3 8}$ was made to undergo a Pd-catalyzed intramolecular enolate heteroarylation to establish the bicyclo[3.3.1] framework. Subsequent Wittig olefination and 
oxidative desilylation provided homoallylic alcohol 41 which was dehydrated with the Burgess reagent. Although the olefination reaction led to an $E / Z$ mixture of products, the desired ( $E$ )-form was the major product. A platinum-catalyzed hydration of the bridgehead cyano group under Ghaffar-Parkins conditions ${ }^{36-37}$ gave the amide 42. Hofmann rearrangement of this compound under the influence of PIFA gave the precursor to (-)-huperzine. Methyl deprotection under standard conditions afforded (-)-huperzine in 35-45\% overall yield.
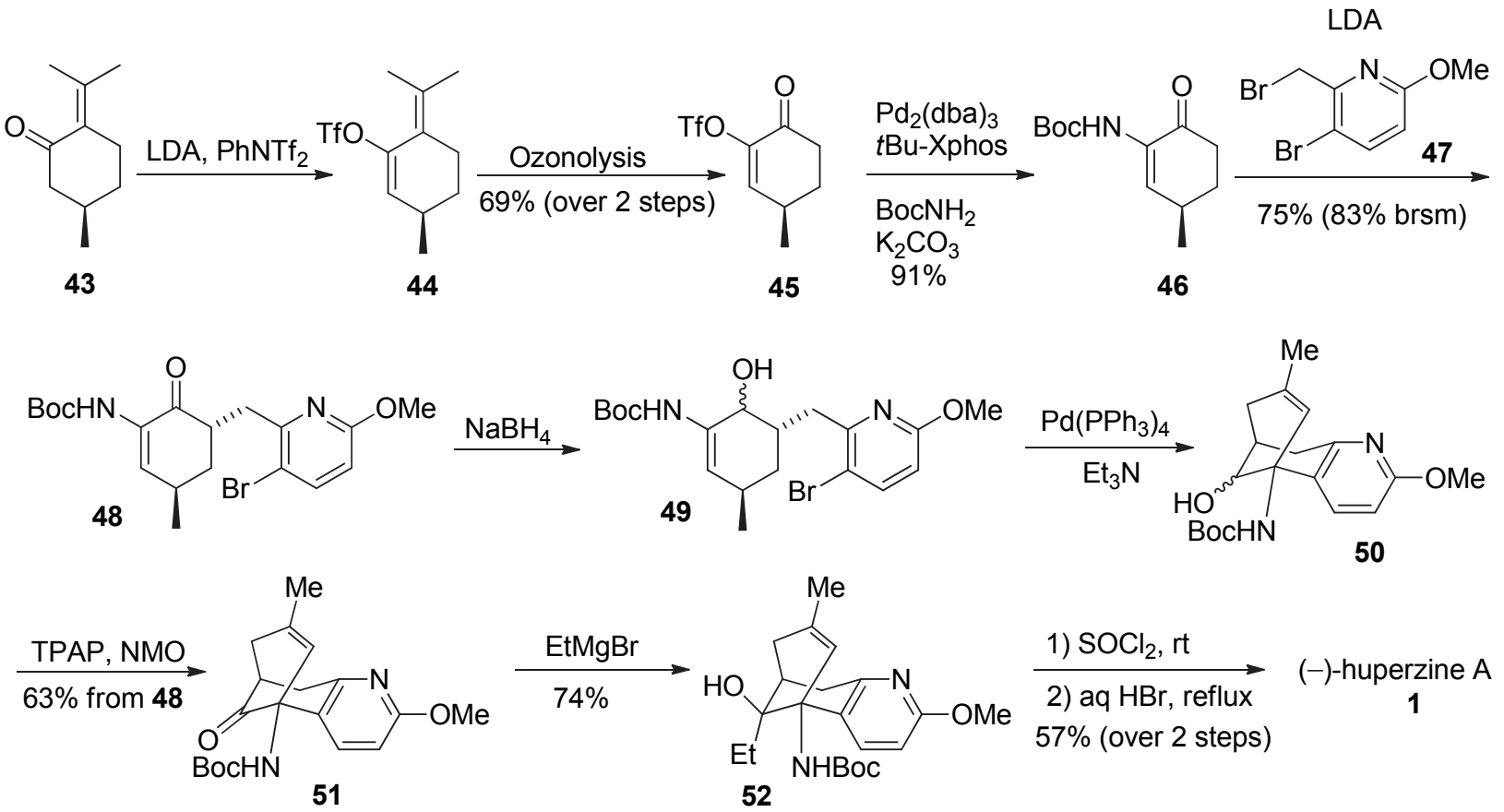

Scheme 7. Sun and Lin's route to (-)-huperzine A.

Sun and Lin's synthesis ${ }^{38}$ of (-)-huperzine A which exploits an intramolecular Heck coupling as the key step emanated from commercially available $(R)$-pulegone (Scheme 7$)$. It was triflylated first and the resulting enol triflate $\mathbf{4 4}$ was subsequently ozonolyzed to give ketone $\mathbf{4 5}$ which underwent a smooth Buchwald-Hartwig coupling to provide carbamate 46. Deprotonation and reaction of the resulting dianion with bromide 47 led to enone 48 with a $>20: 1$ diastereomeric ratio. Subsequent $\mathrm{NaBH}_{4}$ reduction and Pd-catalyzed intramolecular Heck coupling of the diastereomeic alcohols established the bicyclic framework under formation of the secondary alcohol 50. Ley oxidation and Grignard addition of the product ketone $\mathbf{5 1}$ produced the tertiary alcohol 52. Finally, a one pot sequence comprising the treatment of $\mathbf{5 2}$ with $\mathrm{SOCl}_{2}$ followed by exposure to aqueous $\mathrm{HBr}$ led to the formation of (-)-huperzine $\mathrm{A}$ through demethylation, double bond transposition and Boc-removal. This ten step route provided the natural product in $17 \%$ overall yield.

A very similar approach was disclosed by Mann and colleagues ${ }^{39}$ who accomplished a formal total synthesis of huperzine A. As depicted in scheme 8, this route also uses intramolecular Heck 
coupling as the pivotal step in the synthetic sequence which commences with 2-cyclohexenone as the starting material. Baylis-Hillman reaction of 2-cyclohexenone followed by TBS protection and alkylation provided the enone $\mathbf{5 5}$ which was subjected to Luche reduction to prepare the alcohol 56 as a syn/anti mixture. Heck coupling on this diastereomeric alcohol substrates was successfully implemented to establish the requisite bicyclo[3.3.1] skeleton. The major syn isomer of 57 was first TBS protected before subjecting it to a one pot hydroboration-oxidation sequence. Ketone 59 thus obtained was reacted with methylmagnesium iodide and the resulting tertiary alcohol was dehydrated to furnish olefin $\mathbf{6 1}$ as the major regioisomer along with the undesired regioisomer 60. Desilylation and oxidation of the product 1,3-diol led to the formation of a $\beta$ keto acid which was subsequently esterified with diazomethane to produce the $\beta$-keto ester $\mathbf{1 5}$. This route constitutes a formal total synthesis of the natural product since $\beta$-keto ester $\mathbf{1 5}$ was a pivotal intermediate en route to huperzine A. ${ }^{28}$
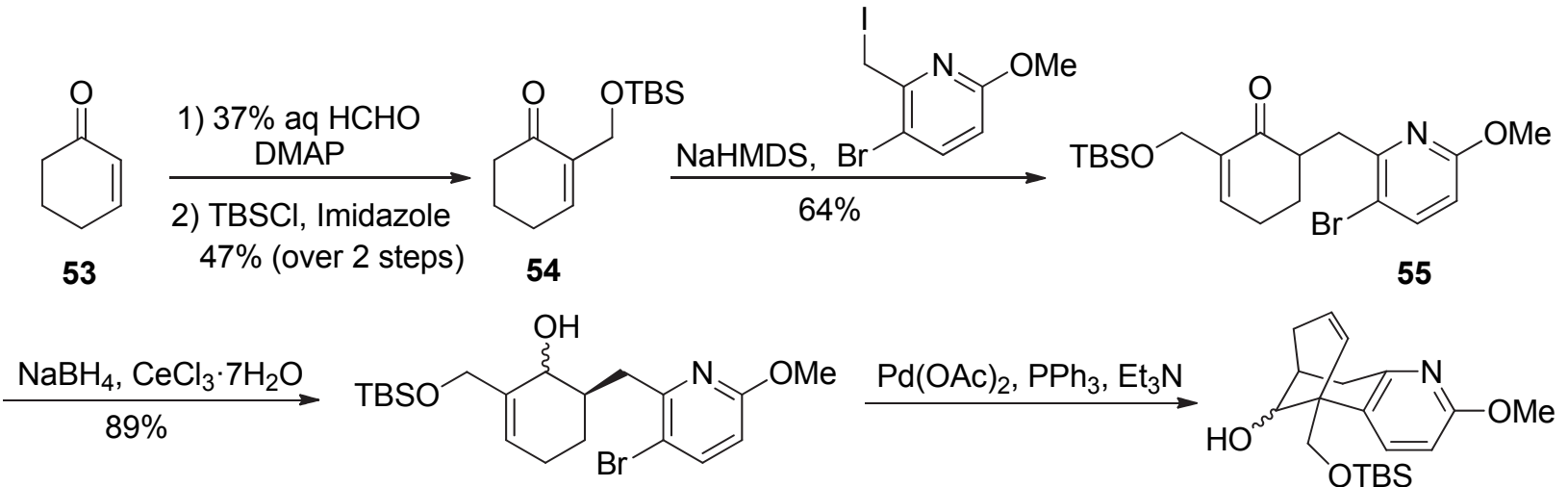

56

syn : anti $98: 2$

57

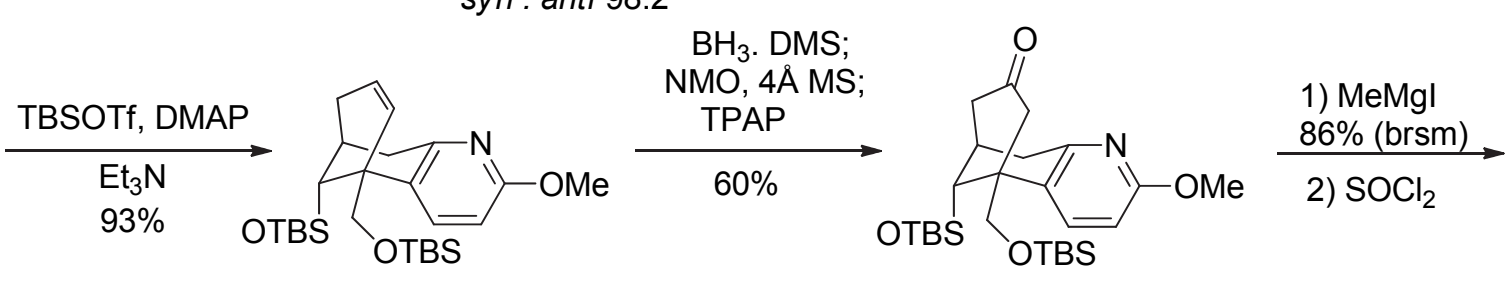

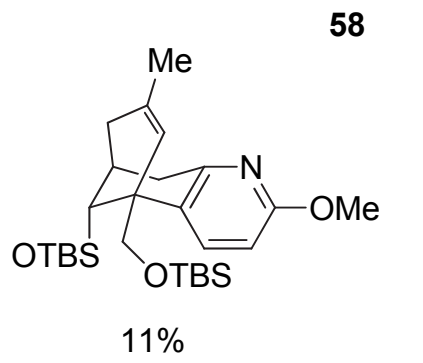

60

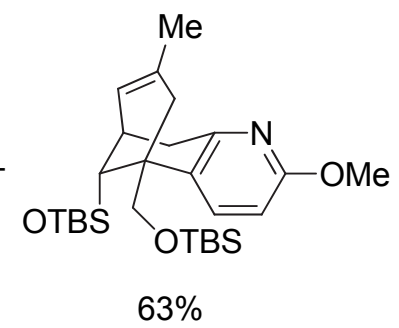

61

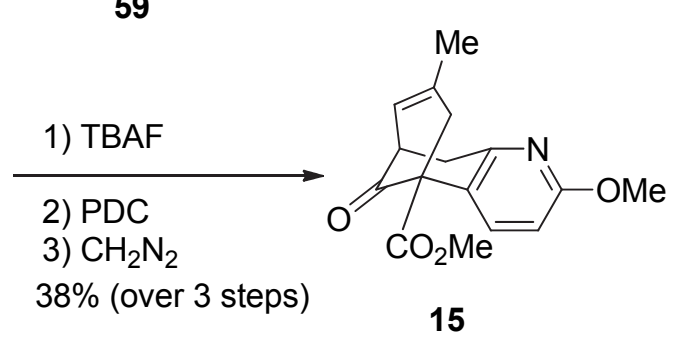

Scheme 8. Mann's formal synthesis of huperzine A. 


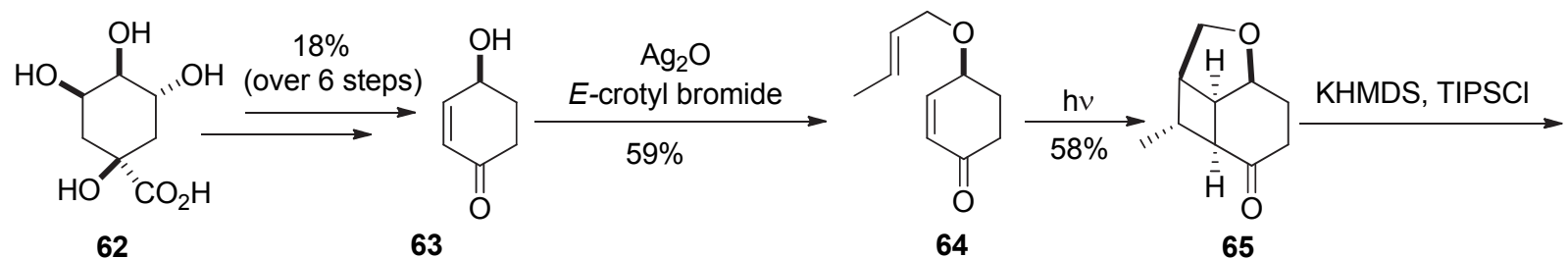

62

63

1) $\mathrm{LiAlH}_{4}$

66 OTIPS

67
3)

69

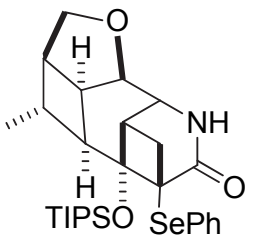

70

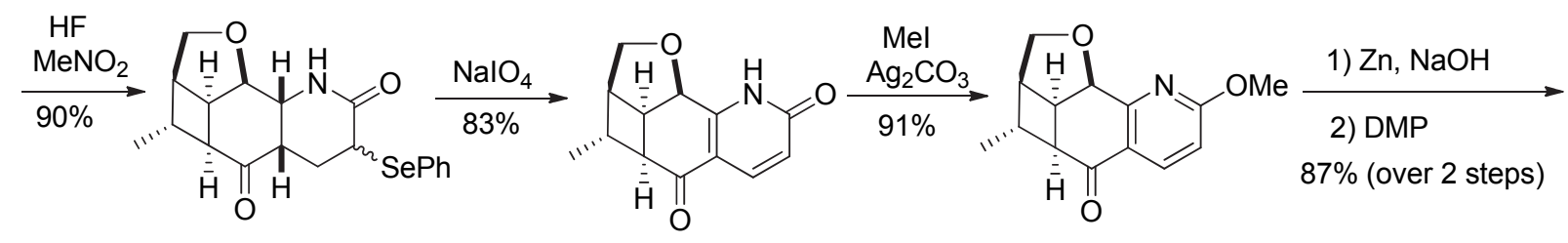

71

72

73

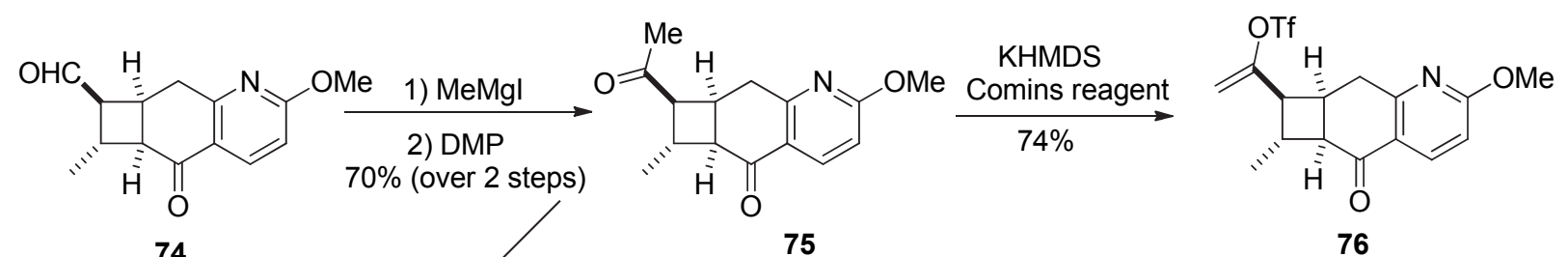

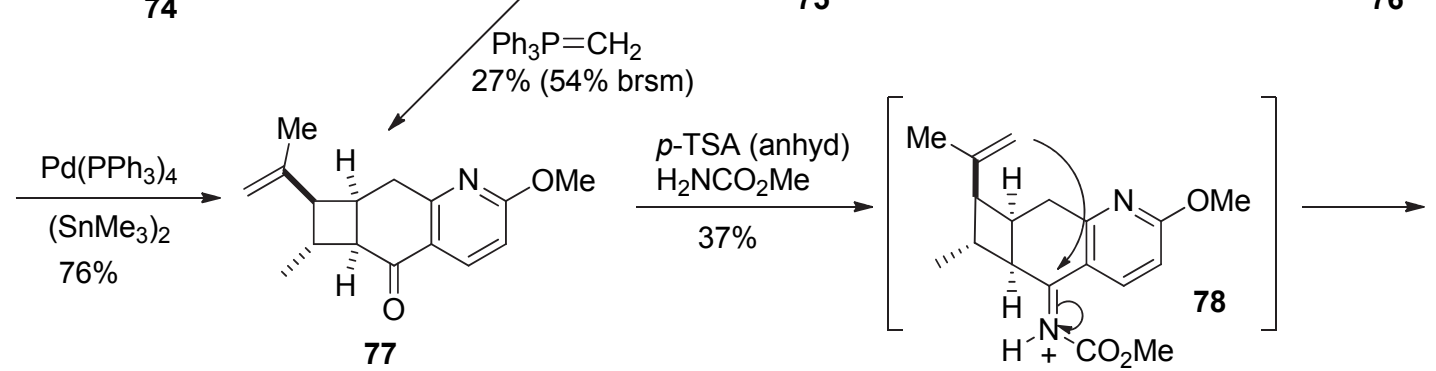<smiles>COc1ccc2c(n1)C[C@H](C)C[C@H](C)C2NC(C)=O</smiles><smiles>COc1ccc(C(C)C)c(NC(=O)c2ccccc2)c1</smiles><smiles>[Mg][Te][Te]</smiles>

Scheme 9. White's asymmetric synthesis of (-)-huperzine A.

White's recent approach which hinges on a domino aza-Prins reaction/cyclobutane fragmentation has recently culminated in a new synthesis of (-)-huperzine A. ${ }^{40}$ As depicted in Scheme 9, White's synthesis starts with $(S)$-4-hydroxycyclohex-2-enone $(\mathbf{6 3})$ which is readily 
synthesized from (-)-quinic acid (62). Enone 63 was alkylated first with $E$-crotyl bromide and the resulting ether was subjected to a photochemical [2+2] cycloaddition to establish the tricyclic framework in intermediate $\mathbf{6 5}$. This was converted into allylic azide $\mathbf{6 7}$ in two steps via silyl enol ether 66. Azide 67 was subsequently converted into amide 69 via reduction to the amine and reaction with acid 68 in the presence of 3,5-dinitrobenzoyl chloride. Amide 69 underwent a smooth [2+2] cycloaddition on exposure to $\mathrm{AlMe}_{3}$ to furnish $\mathbf{7 0}$ which on treatment with $\mathrm{HF}$ led to a desilylation/retro-aldol fragmentation to form the $\alpha$-selenyl $\delta$-lactam 71 as a mixture of diastereomers. $\alpha$-Pyridone $\mathbf{7 2}$ was obtained from selenide $\mathbf{7 1}$ through $\mathrm{NaIO}_{4}$ oxidation/elimination and subsequent $\mathrm{O}$-methylation produced methoxypyridine 73 . The scission of the benzylic $\mathrm{C}-\mathrm{O}$ bond was achieved by exposure of $\mathbf{7 3}$ to activated zinc and methanolic $\mathrm{NaOH}$ to give a $\delta$-hydroxy ketone, the subsequent Dess-Martin oxidation of which furnished aldehyde 74. Diketone $\mathbf{7 5}$ was synthesized from aldehyde $\mathbf{7 4}$ through a two step protocol comprising Grignard addition and oxidation. The product was directly converted into olefin $\mathbf{7 7}$ by Wittig olefination but the yield of the latter step was only $27 \%$. Therefore, the enolate derived from 75 was treated with Comins reagent to form the enol triflate which was subjected to Stille coupling to produce the desired olefin 77 . Reaction of 77 with methyl carbamate and anhydrous $p$-toluenesulfonic acid orchestrated a domino aza-prins/fragmention reaction to assemble the bicyclo[3.3.1] skeleton though the intermediacy of iminium ion intermediate 78. (-)-Huperzine A was obtained upon treatment of the resulting carbamate $\mathbf{8 0}$ with TMSI.

\section{Huperzine B}

Huperzine B is a structural sibling of huperzine A. Despite of its lower acetylcholinesterase inhibitory action, it is also considered an important molecule to combat $\mathrm{AD}$ and dementia mainly because of its higher therapeutic index and its longer duration of action. ${ }^{19}$ Although there are reports concerning the synthesis of structural congeners ${ }^{41-42}$ of huperzine $B$, the number of total syntheses of huperzine B itself remains limited. In addition to the bicyclo[3.3.1]nonane unit fused to a 2-pyridone moiety, huperzine B (2) bears an additional piperidine ring fused to the bicyclo[3.3.1] skeleton.

The first total synthesis of huperzine B appeared in 1997 while Wu and Bai constructed the skeleton via tandem Michael-Mannich reaction. ${ }^{43}$ As outlined in Scheme 10, the key intermediate 86 was synthesized in eight steps from ketoester 81. This starting material was first subjected to a Dieckmann cyclization in the presence of sodium ethoxide and the resulting sodium enolate was further reacted with acrylonitrile to prepare $\beta$-diketone 82. The latter compound was protected first as the methyl enol ether and subsequent ketone reduction followed by acid treatment led to the formation of unsaturated ketone 83. This intermediate was converted into amine $\mathbf{8 5}$ in two steps via protection of the keto group and LAH reduction. Cyclic imine $\mathbf{8 6}$ was formed spontaneously when the ketal in $\mathbf{8 5}$ was cleaved upon exposure to perchloric acid.

Imine 86 reacted smoothly with 1,2,3,4-tetrahydro-6-methyl-2-oxopyridine $\mathbf{8 7}$ in the presence of perchloric acid to form secondary amine $\mathbf{8 8}$ which was protected as a carbamate. 
Subsequent mesylation gave dihydropyridone 89 which was converted into pyridone 90 by the action of sulfuryl chloride followed by the elimination of $\mathrm{HCl}$ from the resulting chloride. The pyridone moiety was protected by $\mathrm{O}$-methylation before inducing a selenoxide elimination. Once the exocyclic double bond was installed, the pyridone moiety was revealed upon demethylation. Finally, the exocyclic double bond in $\mathbf{9 3}$ was isomerized by TMSOTf to afford racemic huperzine $\mathrm{B}$ in $6.6 \%$ overall yield.<smiles>CCOC(=O)CC(CC(C)=O)CC(=O)OCCOc1ccccc1</smiles><smiles>CCOC[C@H]1CC=C(CCCN)C2(C1)OCCCO2</smiles>

84
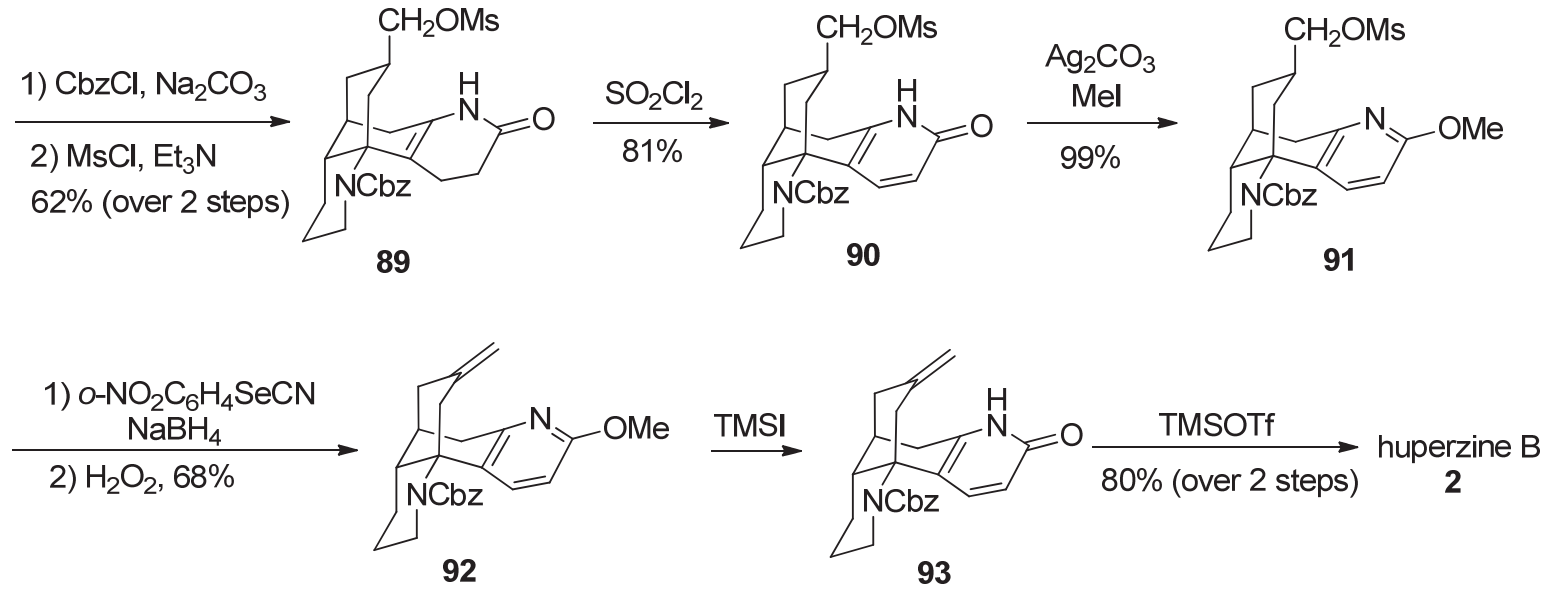

Scheme 10. Bai's synthesis of huperzine B.

A ring-closing metathesis based synthesis of huperzine $\mathrm{B}$ was demonstrated by Lee et al. ${ }^{44} \beta$ Keto ester 14 on Witttig olefination followed by isomerisation of the obtained $E / Z$ mixture provided olefin 94 with the required $(E)$ geometry (Scheme 11). Isomerization of the exocyclic double bond, saponification, Curtius rearrangement and subsequent treatment of the resulting isocyanate with $\mathrm{HCl}$ gave amine 97. This compound was $\mathrm{N}$-alkylated with 4-iodobut-1-ene to produce secondary amine $\mathbf{9 8}$ which underwent smooth ring closing metathesis to the cyclized 
product 99. Huperzine B was obtained from intermediate 99 through hydrogenation and $\mathrm{O}$ demethylation.

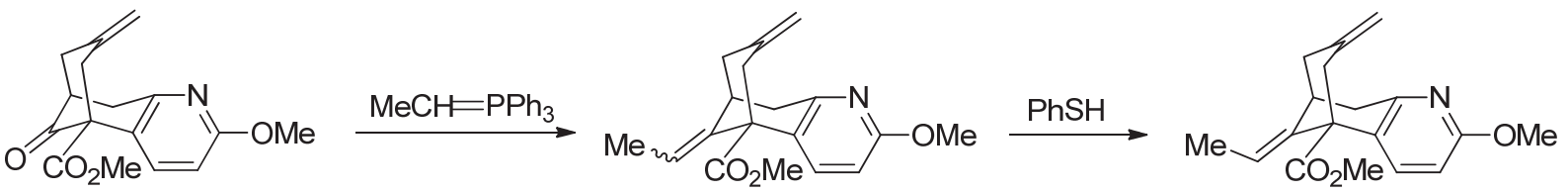

(14)

(16)

(94)

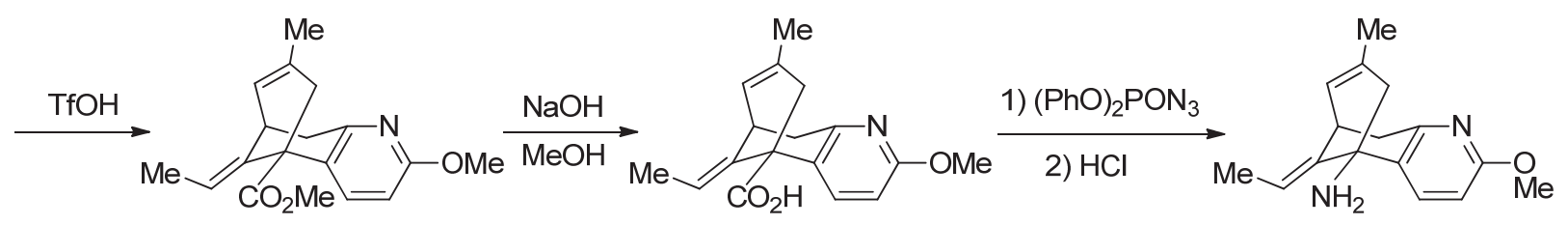

(95)

(96)

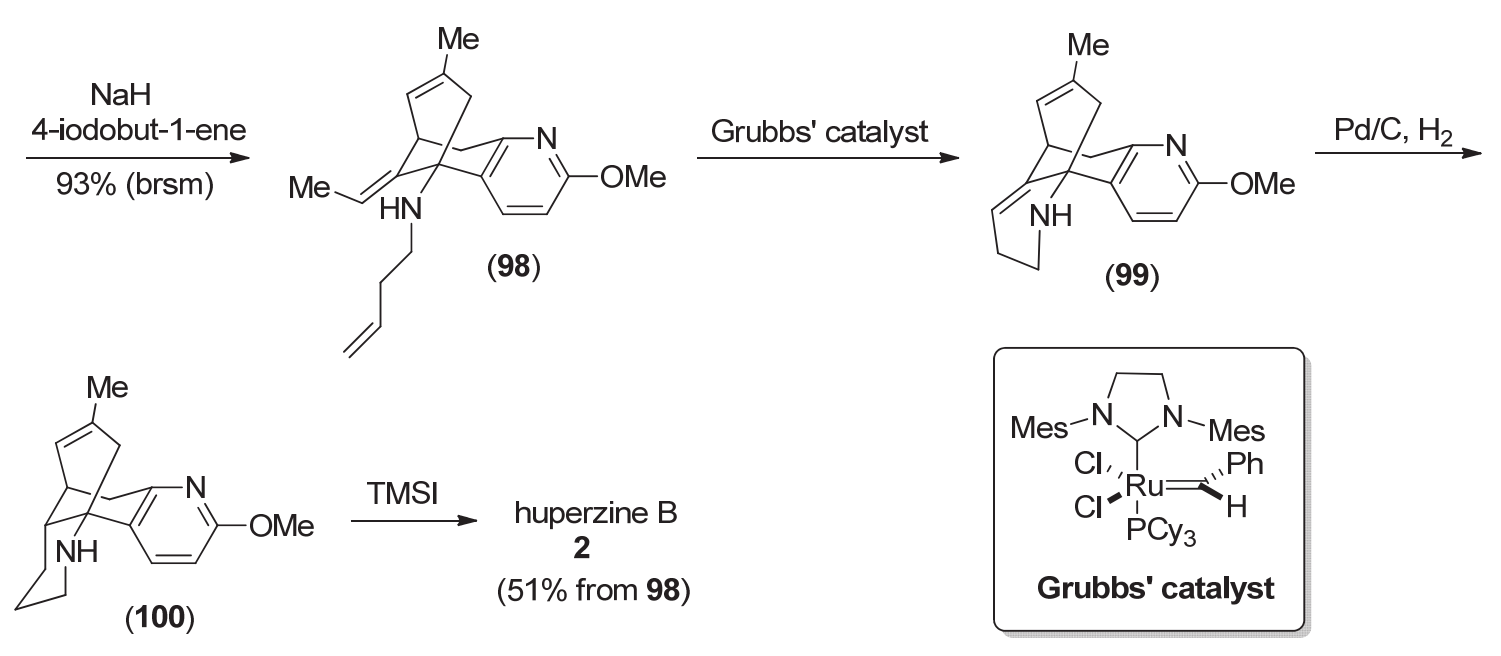

Scheme 11. Lee's synthesis of huperzine B.

In summary, we have presented an overview of the strategies for the total synthesis of huperzine A and B. Complete total syntheses, asymmetric approaches and formal total syntheses of these two alkaloids have been covered. In view of the attractive molecular architecture of these natural products and their strong biological activity, newer strategies will continue to emerge and may well pave the way for the development of new drug candidates to combat Alzheimer's disease and dementia.

\section{References}

1. Kobayashi, J.; Morita, H. In The Alkaloids; Codell, G. A. Ed.; Elsevier Academic Press: Amsterdam, 2005; Vol. 61, p 1.

2. Ma, X.; Gang, D. R. Nat. Prod. Rep. 2004, 21, 752. 
http://dx.doi.org/10.1039/B409720N

3. Wang, H.; Tang, X. C. Acta Pharmacol. Sin. 1998, 19, 27.

4. Tang, X. C.; Han, Y. F. CNS Drug Review 1999, 5, 281. http://dx.doi.org/10.1111/j.1527-3458.1999.tb00105.x

5. Ved, H. S.; Koening, M. L.; Dave, J. R.; Doctor, B. P. Neuroreport 1997, 8, 963.

6. Xiao, X. Q.; Wang, R.; Han, Y.; Tang, X. C. Neurosci. Lett. 2000, 286, 155. http://dx.doi.org/10.1016/S0304-3940(00)01088-0

7. Gordon, R. K.; Nigam, S. V.; Weitz, J. A.; Dave, J. R.; Doctor, B. P.; Ved, H. S. J. Appl. Toxicol. 2001, 21 (Suppl. 1), S47-S51.

http://dx.doi.org/10.1002/jat.805

8. Xiao, X. Q.; Zhang, H. Y.; Tang, X. C. J. Neurosci. Res. 2002, 67, 30. http://dx.doi.org/10.1002/jnr.10075

9. Zhang, H. Y.; Yan, H.; Tan, X. C. Cell Moll. Neurobiol. 2008, 28, 173. http://dx.doi.org/10.1007/s10571-007-9163-z

10. Becker, R. E.; Giacobini, E. Drug Dev. Res., 1988, 12, 163. http://dx.doi.org/10.1002/ddr.430120302

11. Liu, J. S.; Zhu, Y. L.; Yu, C. M.; Zhou, Y. Z.; Han, Y. Y.; Wu, F. W.; Qi, B. F. Can. J. Chem., 1986, 64, 837.

http://dx.doi.org/10.1139/v86-137

12. Peng, Y.; Jiang, L.; Lee, D.-Y. W.; Schachter, S. C.; Ma, Z.; Lemere, C. A. J. Neurosci. Res. 2006, 84, 903.

http://dx.doi.org/10.1002/jnr.20987

13. Wang, R.; Tang, X. C. Neurosignals 2005, 14, 71. http://dx.doi.org/DOI:10.1159/000085387

14. Zhang, H. Y.; Yan, H.; Tang, X. C. Neurosci. Lett. 2004, 360, 21. http://dx.doi.org/10.1016/j.neulet.2004.01.055

15. Zhang, H. Y.; Liang, Y. Q.; Tang, X. C.; He, X. C.; Bai, D. L. Neurosci. Lett. 2002, 317, 143. http://dx.doi.org/10.1016/S0304-3940(01)02437-5

16. Bai, D. Pure Appl. Chem. 2007, 79, 469. http://dx.doi.org/10.1351/pac200779040469

17. Tang, X.-C.; De Sarno, P.; Sugaya, K.; Giacibini, E. J. Neurosci. Res. 1989, 24, 276. http://dx.doi.org/10.1002/jnr.490240220

18. Campiani, G.; Sun, L.-Q.; Kozikowski, A. P.; Aagaard, P.; McKinney, M. J. Org. Chem. 1993, 58,7660 . http://dx.doi.org/10.1021/jo00079a008

19. Yan, X.-F.; Lu, W.-H.; Lou, W.-J.; Tang, X.-C. Acta Pharmacol. Sin. 1987, 8, 117.

20. Liu, J.-S.; Zhou, Y.-L.; Yu, C.-M.; Zhou, Y.-Z.; Han, Y.-Y.; Wu, F.-W.; Qi, B.-F. Can. J. Chem. 1986, 64, 837.

http://dx.doi.org/10.1139/v86-137 
21. Ainge, G. D.; Lorimer, S. D.; Philippa, J. G.; Ruf, L. D. J. Agric. Food Chem. 2002, 50, 491 http://dx.doi.org/10.1021/jf0106087

22. Xia, Y.; Kozikowsky, A. P. J. Am. Chem. Soc. 1989, 111, 4116. http://dx.doi.org/10.1021/ja00193a062

23. Kozikowsky, A. P.; Xia, Y.; Reddy, E. R.; Tückmantel, W.; Hanin, I.; Tang, X. C. J. Org. Chem. 1991, 56, 4636.

http://dx.doi.org/10.1021/jo00015a014

24. Qian, L.; Ji, R. Tetrahedron Lett. 1989, 30, 2089.

http://dx.doi.org/10.1016/S0040-4039(01)93719-0

25. Yamada, F.; Kozikowsky, A. P.; Reddy, E. R.; Pang, Y.-P.; Miller, J. H.; McKinney, M. J. Am. Chem. Soc. 1991, 113, 4695.

http://dx.doi.org/10.1021/ja00012a056

26. Kaneko, S.; Yoshino, T.; Katoh, T.; Terashima, S. Tetrahedron 1998, 54, 5471. http://dx.doi.org/10.1016/S0040-4020(98)00227-0

27. Ding, X.-H.; Li, X.; Liu, D.; Cui, W.-C.; Ju, X.; Wang, S.; Yao, Z.-J. Tetrahedron 2012, 68, 6240. http://dx.doi.org/10.1016/j.tet.2012.05.061

28. Kozikowsky, A. P.; Campiani, G.; Aagaard, P.; McKinney, M. J. Chem. Soc., Chem. Commun. 1993, 10, 860. http://dx.doi.org/10.1039/C39930000860

29. Kaneko, S.; Yoshino, T.; Katoh, T.; Terashima, S. Tetrahedron: Asymmetry 1997, 8, 829. http://dx.doi.org/10.1016/S0957-4166(97)00048-7

30. He, X.-C.; Wang, B.; Yu, G.; Bai, D. Tetrahedron: Asymmetry 2001, 12, 3213. http://dx.doi.org/10.1016/S0957-4166(02)00006-X

31. Chassaing, C.; Haudrechy, A.; Langlois, Y.; Tetrahedron Lett. 1999, 40, 8805. http://dx.doi.org/10.1016/S0040-4039(99)01874-2

32. Haudrechy, A.; Chassaing, C.; Riche, C.; Langlois, Y. Tetrahedron 2000, 56, 3181. http://dx.doi.org/10.1016/S0040-4020(00)00227-1

33. Lee, I. Y. C.; Jung, M. H.; Lee, H. W.; Yang, J. Y. Tetrahedron Lett. 2002, 43, 2407. http://dx.doi.org/10.1016/S0040-4039(02)00270-8

34. Koshiba, T.; Yokoshima, S.; Fukuyama, T. Org. Lett. 2009, 11, 5354. http://dx.doi.org/10.1021/o19022408

35. Tun, M. K. M.; Wüstmann, D.-J.; Herzon, S. B. Chem. Sci. 2001, 2, 2251. http://dx.doi.org/10.1039/C1SC00455G

36. Ghaffar, T.; Parkins, A. W. Tetrahedron Lett. 1995, 36, 8657. http://dx.doi.org/10.1016/0040-4039(95)01785-G

37. Ghaffar, T.; Parkins, A. W. J. Mol. Catal. A. 2000, 160, 249. http://dx.doi.org/10.1016/S1381-1169(00)00253-3

38. Ding, R.; Sun, B.-F.; Lin, G.-Q. Org. Lett. 2012, 14, 4446. http://dx.doi.org/10.1021/ol301951r 
39. Lucey, C.; Kelly, S. A.; Mann, J. Org. Biomol. Chem. 2007, 5, 301. http://dx.doi.org/10.1039/B615059D

40. White, J. D.; Li, Y.; Kim, J.; Terinek, M. Org. Lett. 2013, 15, 882. http://dx.doi.org/10.1021/o1400012s

41. Rajendran, V.; Rong, S.-B.; Saxena, A.; Doctor, B. P.; Kozikowski; A. P. Tetrahedron Lett. 2001, 42, 5359.

http://dx.doi.org/10.1016/S0040-4039(01)01008-5

42. Rajendran, V.; Saxena, A.; Doctor, B. P.; Kozikowski,; A. P. Bioorg. Med. Chem. Lett. 2002, $12,1521$.

http://dx.doi.org/10.1016/S0960-894X(02)00204-4

43. Wu, B.; Bai, D. J. Org. Chem. 1997, 62, 5978.

http://dx.doi.org/10.1021/jo970248f

44. Lee, I. Y. C.; Hong, J. Y.; Jung, M. H.; Lee, H. W. Tetrahedron Lett. 2004, 45, 285. http://dx.doi.org/10.1016/j.tetlet.2003.10.169

\section{Authors' Biographies}

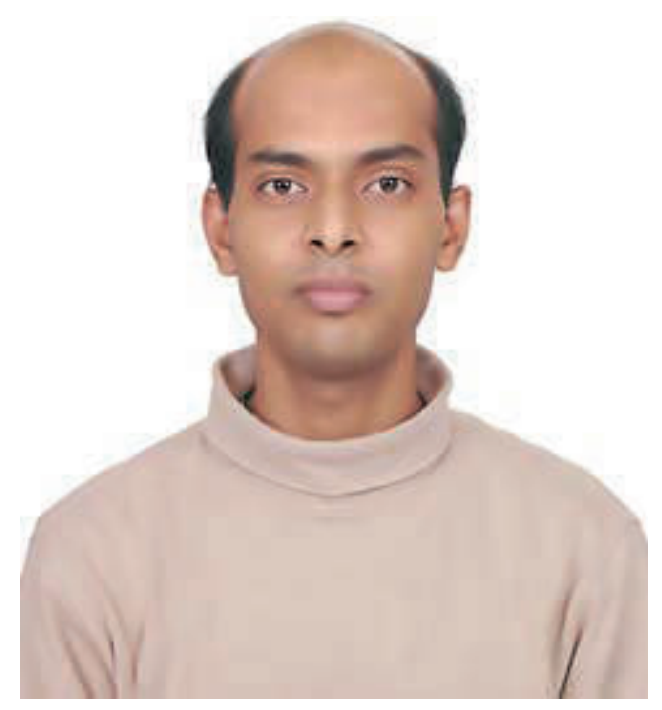

Shariar Md. Abu Sohel received his B.Sc. and M.Sc. in chemistry from Visva Bharati University. He received a Ph.D. in 2009 from National Tsing-Hua University, Taiwan for his research work on metal catalyzed reactions under the supervision of Prof. Rai-Shung Liu. After continuing in the same laboratory as a postdoctoral fellow, he moved to France in September, 2011 to work as a postdoctoral fellow in the laboratory of Prof. Sébastien Tilloy. Since September, 2012, he has been working as a postdoctoral fellow in the laboratory headed by Prof. Till Opatz at the Johannes Gutenberg University of Mainz, Germany. 


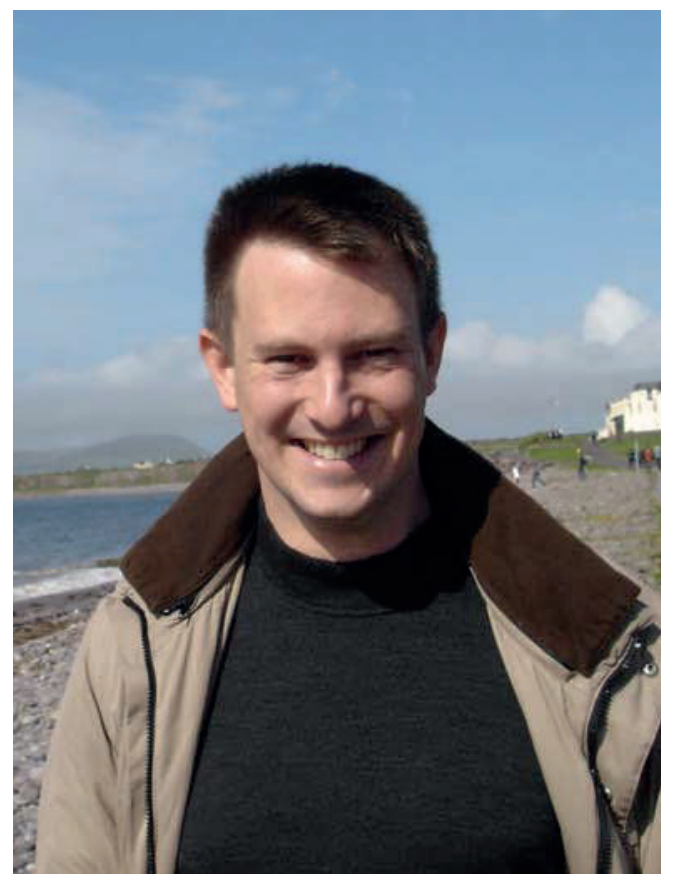

Till Opatz was born in Bad Homburg, Germany, in 1973. He obtained his diploma degree in 1997 with Professor Johann Mulzer at the University of Frankfurt and his doctorate in 2001 with Professor Horst Kunz at the University of Mainz. After a postdoctoral stay with Professor Rob Liskamp, University of Utrecht (The Netherlands), he completed his Habilitation at the University of Mainz in 2006. In 2007, he was appointed as a professor of organic chemistry at the University of Hamburg. In April 2010, he moved to the Johannes Gutenberg University of Mainz. His research interests are new synthetic methods, the synthesis of biologically active compounds and the chemistry of natural products. 